\title{
ORDEN JURÍDICO E IDENTIDAD POLÍTICA EN LOS ALBORES DE LA RECEPCIÓN DEL DERECHO COMÚN* (SOBRE LOS FORAIS DE COIMBRA, LISBOA Y SANTARÉM)
}

\author{
ANA Ma BARRERO GARCÍA \\ Instituto de Historia CCHS (CSIC)
}

RESUMEN: Aunque la bistoriografía portuguesa ba prestado especial atención al expreso reconocimiento del reino de Portugal por parte del papa Alejandro III, este becho nunca se ha puesto en relación con otro coetáneo y no menos singular como lo es la concesión simultánea de fueros a las poblaciones de Coimbra, Lisboa y Santarém por parte del rey "Fundador» Alfonso Enríquez. El planteamiento como hipótesis inicial de trabajo de la existencia de una posible relación de causalidad entre ambos hechos y la búsqueda de su verificación en el análisis crítico de los documentos que dan cuenta de las actuaciones pontificia y regia conduce a resultados sorprendentes sobre el proceso de elaboración de estos forais en los que sin perjuicio de la tradición jurídica e histórica se da entrada a los principios del Derecho común para presentar al primer rey de los portugueses como «Imperator in regno suo».

Palabras Clave: Portugal. Coimbra. Lisboa. Santarém. Alfonso I. Orden jurídico. Forais. Derecho común. Recepción.

ABSTRACT: Although Portuguese historians have already paid special attention to the recognition of Portugal as a kingdom by Pope Alexander III, this very fact has not yet been connected to another singular contemporary fact: the simultaneous concession of "forais» to the towns of Coimbra, Lisbon and Santarem, by king Alfonso Enríquez. The assumption, as an initial working hypothesis, that there is a possible causal relationship between both facts, as well as seeking to verify such hypothesis by means of a critical analysis of the documents respectively embodying the action of both Pope and King, lead to remarkable results about the redaction process of these «forais», where, while keeping within the bounds of the current historical and juridical traditions, it also occurs the reception of the «Ius commune» principles, depicting the first Portuguese king as «Imperator in regno suo».

KEY WORDS: Portugal. Coimbra. Lisbon. Santarem. Alfonso I. Juridical order. Forais. Ius commune. Reception. 


\section{Planteamiento}

La expresión mítica (y con ello sublimación) de la identidad política de los pueblos mediante actuaciones relativas al derecho ha devenido en tópico de la historiografía tradicional sobre el origen de los reinos y territorios peninsulares. No ha sido este el caso del regnum portugalensis, quizá no tanto por falta de intención como por ausencia de mitos. De ahí el recurso obligado a los hechos y en especial al del reconocimiento de una situación fáctica por la autoridad entonces aceptada por universal, el papa Alejandro III ${ }^{1}$.

Por otra parte, en el Portugal de los siglos XI a XIII, lo mismo que en los otros reinos, la intervención de los poderes jurisdiccionales en el proceso de creación normativa se presenta íntimamente vinculada a la recuperación y repoblación de los territorios, generándose un sistema jurídico de carácter eminentemente casuista y de alcance local, sin perjuicio de que con el tiempo llegue a alcanzarse una relativa uniformidad normativa por efecto de la difusión de determinados estatutos, que se ofrecen como favorables, tanto a los ojos de los mandatarios que los conceden, como a los de las propias poblaciones que los solicitan. Este fenómeno de difusión normativa, general en la península, trasciende las fronteras de los reinos y se hace tanto más intenso cuanto más se avanza en el proceso de escrituración de este derecho ${ }^{2}$. Por ello no es de extrañar que el sistema de los forais se muestre al historiador como vicario en gran

SIGLAS Y ABREVIATURAS:

AEM, Anuario de Estudios Medievales.

AHDE, Anuario de Historia del Derecho Español.

BFDC, Boletim da Faculdade de Direito de Coimbra.

DHP, Dicionário de História de Portugal dirigido por J. SERRÃO, Porto, Livraria Figueirinhas, 1985.

$D M P$, Documentos medievais portugueses: Documentos dos condes portugalenses e de D. Afonso Henriques A. D. 1095-1185 vol 1. Texto/ Introdução diplomática e notas pelo académico de número R. P. DE Azevedo, Lisboa, Academia Portuguesa da Historia, 1958-1962.

Docs. Sancho I, Azevedo, R. P., Costa, A. de J. DA, Rodrigues Pereira, M.: Documentos de D. Sancho I (1174-1211) vol. I, Coimbra, Centro de Historia da Universidade, 1979.

MGH, SS, Monumenta Germaniae Historica, Scriptores rerum Germanicarum in usum scholarum separatim editi. (http://www.dmgh.de/).

MGH, LC, Monumenta Germaniae Historica, Leges, Constitutiones et acta.

PMH, LC,Portugaliae Monumenta Historica a saeculo octavo post Christum usque ad quintum decimum, iussu Academiae Scientiarum Olisiponensis edita I, Leges et consuetudines, Lisboa 1856, (reimpr. facs. 1980).

RABM, Revista de Archivos Bibliotecas y Museos.

RPH, Revista Portuguesa de Historia.

RUC, Revista da Universidade de Coimbra.

1 Mediante la bula Manifestis probatum (PT-TT-BUL/16/20; http://ttonline.iantt.pt/dtematico. htm; ed. ACAdemia Portuguesa Da Historia, $8^{\circ}$ Centenario do Reconhecimento de Portugal pela Santa Sé, (Bula «Manifestis probatum»- 23 de mayo de 1179. Commemoração académica, Lisboa, 1979, pp. 231-32).

2 Cfr. Barrero García, A.: «El proceso de formación del derecho local medieval a través de sus textos: Los fueros castellanos leoneses» en IGLEsia DuARTE, J. I. De La, coord.: I Semana de Estudios Medievales. Nájera 1990, Actas, Logroño, 2001, pp. 91-131. 
medida del de los fueros castellano-leoneses y en especial de los de Ávila y Salamanca ${ }^{3}$. Junto a los textos portugueses que reconocen esta procedencia, por exclusión, los forais de las localidades en los que no se indica expresamente o no se pone de manifiesto un origen determinado (lo que ocurre con mayor frecuencia en las de la vertiente atlántica ${ }^{4}$ ) reciben la consideración de netamente portugueses, cuando no de «nacionales», con especial referencia a los que se dicen otorgados por Alfonso I a Coimbra, Lisboa y Santarém en el mes de mayo de $1179^{5}$. Y ciertamente estos tres fueros, prácticamente idénticos en su formulación, presentan una notoria singularidad no sólo (o quizá no tanto) en virtud de su contenido sino también por haber sido concedidos de forma simultánea a dichas localidades, por otra parte de especial significado en la historia de Portugal ${ }^{6}$. Se trata de un hecho único, sin paralelo en los otros reinos, hecha salvedad del protagonizado por Alfonso X cuando a lo largo del mes de julio de 1256 expidió a varias villas de sus dominios sendos privilegios, concediendo el Fuero Real bajo la denominación de Fuero del Libro ${ }^{7}$. Tiempos demasiado distantes y circunstancias muy distintas las de uno y otro monarca para pretender una relación entre ambas actuaciones regias más allá de una coincidencia casual. Pero aún sin mediar prejuicio alguno en este sentido, resulta difícil encajar este proceder del Conquistador luso en el marco de una política dirigida tan sólo a cubrir las expectativas de o sobre unas comunidades vecinales concretas, como se ha venido admitiendo comúnmente ${ }^{8}$. La similitud de contenidos y

3 Para una visión de conjunto cfr. MARTínez DíEZ, G.: «Recepción de fueros locales castellanos en territorio portugués» en BFDC 58 (1982) 451-70, y BARRERO GARCíA, A. y ALONSO MARTín, Ma . L.: Textos de derecho local español en la Edad Media. Catálogo de fueros y costums municipales, Madrid 1989; sobre la difusión del fuero de Ávila, BLASCO, R.: «El problema del fuero de Ávila» en RABM 60 (1954) 7-32; sobre la difusión y relación textual de los forais que siguen el fuero de Salamanca, BARRERo GARCía, A.: «El fuero breve de Salamanca: sus redacciones» en AHDE 50 (1980) 439-67.

4 Cfr. a estos efectos la Carta de los concelhos medievais portugueses (Tentativa de sistematização) elaborada por el profesor Sousa Soares, reproducida en DHP II, Porto 1981, s.v. Concelhos

5 Así Herculano, A.: Historia de Portugal IV, Lisboa 1862, 2a ed. (repr. digital MatToso, J. comp.: Obras clásicas para la Historia de Portugal, Colección Clásicos Tavera, Serie 6, vol. I ) lib. VIII, parte III, p. 257.

6 Su edición en $P M H, L C$, pp. 405-19 y en DMP, no 355-357, pp. 437-50.

7 El 2 de julio aparece expedido el de Alcaraz, el 19 los de Peñafiel y Soria, el 20 el de Arévalo, el 21 el de Cuellar, el 22 el de Atienza, el 23 el de Buitrago, el 24 el de Hita, el 26 el de Alarcón y el 27 los de Burgos y Trujillo. Cfr. BARrero García, A. y Alonso MARTín, M ${ }^{a}$ L.: Textos de derecho local (cit. supra nota 3), pp. 563-64 y voces correspondientes.

8 La crítica ha dedicado atención a estos textos desde una óptica localista, centrando el interés en establecer la prioridad del texto de una población sobre los de las otras a fin de determinar el lugar originario de las normas, perspectiva esta muy arraigada entre los estudiosos (no sólo localistas) en las décadas centrales del siglo XX. El debate en torno a estos textos no dista en perspectiva, método etc. del sostenido sobre la prioridad foral entre las ciudades de Cuenca y Teruel; sobre ello cfr. BARRERO GARCíA, A.: «Los fueros de Teruel y Albarracín (Apunte historiográfico)» en LATORRE CiríA, J. M. coord.: Los Fueros de Teruel y Albarracín. Actas de las 
coincidencia en la data de los documentos pueden llevar al lector de los mismos a presumir una actuación del rey distante, si es que no ajena por completo, al proceso repoblador, dirigida a ciudades de importancia política (Coimbra y Lisboa) y a un enclave estratégico de primer orden (Santarém), haciendo valer su autoridad con el fin de recabar de dichas poblaciones los (son los términos de los documentos) regalia iura. Cabe suponer también que el acto hubo de revestir cierta solemnidad a juzgar por la apariencia de los diplomas que lo recogen. Y esto sucedía, se nos dice, en el mismo mes de mayo en que Alejandro III toma bajo la protección de la Santa Sede el reino de Portugal cum integritate honoris regni et dignitate que ad reges pertinet. ¿Casualidad o causalidad? ¿cabría interpretar la concesión de estos forais que nos ocupa como efecto inmediato de la bula papal? ¿se sirvió de ellos el rey Fundador para hacer patente a sus vasallos, representados por los habitantes de Coimbra, Lisboa y Santarém, el alcance de su dignidad y autoridad, ahora tan plenamente reconocida por la instancia suprema de la cristiandad?

Los documentos tienen la palabra.

\section{LOS FUEROS DE COIMBRA, LISBOA y SANTARÉM. SU ANÁlisis CRÍTICO}

\subsection{Su crítica diplomática}

El acto (probablemente único, dada la naturaleza del mismo) de concesión de fueros a los habitantes de Coimbra, Lisboa y Santarém por Alfonso I tuvo lugar residiendo la corte en Coimbra, un día indeterminado del mes de mayo de 1179. De él ha quedado constancia en los documentos expedidos por la escribanía regia de forma individualizada para cada una de las comunidades beneficiarias del mismo, si bien no en los diplomas originales, sino a través de copias posteriores. Son éstas las realizadas sobre los ejemplares presentados a la cancillería de Alfonso II por los respectivos concejos para su confirmación y su posterior registro en 1217. Pero además, los forais de Lisboa y Santarém se conservan en sendos diplomas reputados por la crítica de originales de cancillería9. De factura muy similar, no exenta de complejidad, ambos diplomas, así como el del foral de Leiria, relacionado con ellos por diversos conceptos ${ }^{10}$, presentan algunos signos expresivos de su carácter solemne a la vez que garantes de su autenticidad. Se trata, por una parte, de la presencia de un sello rodado real; por otra, del asiento en los diplomas de la confirmación de los mismos por

\footnotetext{
Jornadas de estudio celebradas en Teruel y Albarracín los días 17, 18 y 19 de diciembre de 1998, Teruel, 2000, pp. 269-279.

9 Cfr. DMP, nota LVII, pp. 762-67.

10 Este foral, atribuido a Sancho I y datado en 1195 , reproduce de forma muy similar el texto de estos forais. Como en el caso de los de Lisboa y Santarém se conserva en un diploma que figura confirmado por Alfonso II en 1214, además de en la confirmación de Alfonso II en 1217. Su edicion en Docs. Sancho I, $\mathrm{n}^{\circ} 78$, pp. 120-24
} 
Alfonso II en 1214, con las cláusulas documentales y suscripciones pertinentes. Los orificios en el pliegue inferior de los pergaminos son indicio de la imposición de un sello colgante, que en justa correspondencia con la cláusula de validación del texto confirmatorio sería el de plomo de la cancillería de Alfonso II $^{11}$.

Tomados estos elementos como evidencias de la autenticidad de estos diplomas $^{12}$, los estudiosos han dirigido sus esfuerzos a explicar y justificar algunas de las anomalías de carácter formal que en ellos se aprecian, y a distinguir y situar en el tiempo los diversos textos que los integran. Siguiendo como guía el diploma de Santarém (por razón de la mayor complejidad en su configuración), éstos son:

$1^{\circ}$ El foral de Alfonso I fechado en Coimbra en mayo de 1179. Dato a tener en cuenta es el que en este diploma aparezcan intercaladas rúbricas alusivas al contenido de sus disposiciones sin solución de continuidad respecto de éstas, de tal forma que sólo el uso de tinta roja las diferencia del enunciado normativo. En el diploma de Lisboa las rúbricas, también en tinta roja, se presentan exentas del cuerpo normativo en el margen derecho del pergamino ${ }^{13}$. Dichas rúbricas no figuran en los instrumentos procedentes de la confirmación de $\mathrm{Al}$ fonso II de 1217.

$2^{\circ}$ Dos cláusulas de carácter normativo que en el foral de Coimbra figuran incorporadas en el texto anterior. El orden de exposición de estas cláusulas del diploma de Santarém es el mismo en el de Lisboa así como en las confirmaciones de 1217.

$3^{\circ}$ Una cláusula de confirmación del fuero por Sancho I, actuando junto a su esposa Dulce y sus hijas, sin mención de sus nombres. No se acompaña de la correspondiente datación. También se encuentra en el diploma de Lisboa y en las confirmaciones de $1217^{14}$.

$4^{\circ}$ Una segunda intervención de Sancho I de alcance normativo, actuando con sus hijos e hijas, sin mención expresa de sus nombres. Tras el desarrollo de las disposiciones no figura cláusula de datación. Este mismo cuerpo normativo se encuentra en el diploma de Lisboa, pero aquí presentado como carta patente dirigida a las autoridades y comunidad vecinal, fechada en Guimarães, en agos-

\footnotetext{
11 Ego Alfonsus Dei gratia Portugalensis rex...hanc cartam...roboro et confirmo et sigillo meo plumbeo communiri facio.

12 Si bien se deja sentir cierta ambigüedad al respecto que resulta desconcertante; así en $D M P$, nota LVII, p. 764 en relación con el diploma: Todos esses dados...constituyen prova de que o exemplar $(A)$ estava a fazer as vezes do original. La misma apreciación sobre el de Lisboa en p. 766.

13 Aunque presentan una formulación muy similar en uno y otro texto, ésta no es siempre coincidente, como tampoco lo son en número ya que el de Santarém ofrece 41, frente a las 33 del de Lisboa.

14 En la versión de Lisboa confirmada en 1217 esta cláusula con su correspondiente nómina de tres confirmantes aparece situada al final del documento objeto de la confirmación, seguida de inmediato del texto confirmatorio de Alfonso II.
} 
to de $1204^{15}$. No obstante, no aparece recogido en la versión de 1217 salvo en su última norma que, sin embargo, no figura en el de Santarém.

$5^{\circ}$ Sin mediar cláusula formal alguna e introducida por la frase «Qui presentes fuerunt» sigue la relación de confirmantes dispuestos en dos columnas. En los últimas siete suscripciones (cuatro confirmantes y tres testigos) de la primera columna y los dos testigos finales de la segunda se percibe un cambio en la letra. En el diploma de Lisboa también se aprecia un cambio de letra, que se mantiene hasta la confirmación de Alfonso II.

$6^{\circ}$ Una cláusula de carácter normativo que se sitúa entre las columnas de los confirmantes, escrita con el mismo tipo de letra que la introducida en las suscripciones produciendo un cambio respecto de lo anterior, según se ha advertido en el punto precedente ${ }^{16}$. Esta disposición coincide con algunas variantes con la penúltima de la carta patente a Lisboa antes reseñada.

$7^{\circ}$ Un sello rodado, en tinta roja, colocado entre las columnas de confirmantes en su parte inferior. En él aparecen inscritos con título regio los nombres de don Sancho y don Alfonso en posición de aspas cruzadas, y los de doña Dulce, doña Teresa y doña Sancha en los espacios triangulares dejados libres por aquéllos. En los ejemplares de 1217 no se constata la presencia de este sello ni de su correspondiente leyenda.

$8^{\circ}$ Finalmente, a renglón seguido y con letra distinta a la de los asientos precedentes, el breve texto y cláusulas de la confirmación de Alfonso II.

En lógica correspondencia con el criterio de autenticidad que se atribuye a estos diplomas, no se ha planteado alternativa a la de su elaboración en los medios cancillerescos regios. Sin embargo, un detenido análisis de estos diplomas hace posible otra apreciación de los mismos, pues los elementos antes destacados que han sido percibidos por la crítica como fundamento de dicha condición podrían resultar no serlo. No lo es, sino muy al contrario, la presencia del sello rodado, ya que su leyenda no se compadece con ninguna de las actuaciones reales recogidas en los diplomas ${ }^{17}$. Además, que elemento tan significativo no

15 Tampoco se ha incluido en las ediciones del foral. Su edición en Docs. Sancho I, $\mathrm{n}^{\mathrm{O}}$ 155, pp. 242-43; su traducción en CAETANO, M.: A administração municipal de Lisboa durante a primera dinastia (1179-1383), Lisboa, 1981, $2^{\mathrm{a}}$ ed., $\mathrm{n}^{\mathrm{o}}$ II, pp. 124-25.

16 No obstante, esta disposición aparece incorporada al cuerpo normativo en el diploma de la confirmación de 1217 .

17 Este dato, que no ha pasado desapercibido a los editores y estudiosos de estos textos, ha sido objeto de lecturas diversas. Puesto que para el anotador de la edición en PMH, LC (al parecer Herculano) el texto de los diplomas habría sido elaborado en la cancillería de Alfonso I, explica la presencia en el sello del nombre de los dos reyes en lugar preferente, por la asociación del infante don Sancho al gobierno del reino, circunstancia que efectivamente se produjo en mayo de 1169 tras el asedio de Badajoz (vid. CostA, A. de J. DA: «La Chancellerie royale portugaise jusqu'au milieu du XIIIe siècle» en $R P H$ 15, 1975, 144). ReUTER, A. E.: Chancelarias Medievais Portuguesas I, Documentos da Chancelaria de Afonso Henriques, Coimbra, 1938, $\mathrm{n}^{\circ} 243$, p. 367, se expresa a este respecto con mayor ambigüedad sin decidirse por su procedencia de una u otra cancillería, si bien señala la singularidad de la presencia del nombre de las infantas en un sello de Alfonso I. No obstante, el hecho 
se registre en los ejemplares resultantes de las confirmaciones de 1217 , así como que, en el caso de Santarém, su factura haya de relacionarse en función de la tinta roja utilizada con las rúbricas alusivas al contenido normativo, elemento ajeno por completo a las prácticas escriturarias de documentos de esta naturaleza en los escritorios regios ${ }^{18}$, llevan a la conclusión de que, cuanto menos, estos elementos — sello y rúbricas — no figuraban en los instrumentos originarios utilizados en la elaboración de estos diplomas.

Por lo que respecta a la confirmación de estos diplomas en 1214 , las reticencias que despierta su presencia en ellos no lo son tanto de carácter formular como respecto de la verosimilitud de una actuación de Alfonso II en este sentido en la fecha indicada ${ }^{19}$. Si nos atenemos a los datos documentales disponibles habría que pensar una vez más en una actuación regia verdaderamente singular, ya que no sólo no ha quedado constancia de una acción similar para otras comunidades, sino que en ese año la actividad de la cancillería regia parece haber sido muy escasa ${ }^{20}$. Por otra parte, en relación con la respuesta de estas comunidades a la orden de confirmación general de Alfonso II, no puede dejar de extrañar tanto que las autoridades vecinales se sintieran obligadas a atender a la demanda regia cuando ya contaban con su confirmación expresa debidamente documentada no demasiado tiempo atrás, como que para su tramitación se presentaran unos instrumentos en los que no se daba constancia de ello ${ }^{21}$.

de que en su edición (reconstruida) de las cláusulas protocolarias de los documentos incluya la leyenda del sello rodado, parece indicar que se inclina por la primera opción. Ninguno de estos autores destaca la incoherencia de este sello con el hecho de que el documento recoja una actuación del rey en solitario. Por su parte Azevedo considera que el sello se corresponde con la cláusula confirmatoria de Sancho I (DMP, nota LVII, p. 764), sin tener en cuenta que ésta presenta al rey actuando cum uxore mea regina domna D.ulciat et cum filiabus meis, (sin que en ello se ofrezca variante alguna en ninguno de los ejemplares de estos fueros) lo que no se corresponde tampoco con la presencia en la leyenda del en este caso infante Alfonso. Además la leyenda no se adecua a la otra intervención del rey Sancho, ya que en esta ocasión, si bien actua cum filiis et filiabus se hace sentir la ausencia de la reina.

18 La introducción de rúbricas en los textos forales suele deberse a la actuación sobre los mismos de los prácticos locales, pero faltan en los documentos de este carácter que se presentan como diplomas de las cancillerías reales.

19 No obstante llama la atención que no se mencione también junto a los infantes Sancho y Leonor al infante Alfonso, nacido en 1210.

20 Entre los documentos forales recogidos en los $P M H, L C$ ningún otro, salvo los que aquí nos ocupan y el similar de Leiria, aparece otorgado ni tampoco confirmado en dicho año. De documentos de otro carácter sólo he tenido conocimiento del primer testamento del monarca, con fecha el 27 de junio. (ed. COSTA, A. de J. DA: «Os mais antigos documentos escritos em portugues» en RPH 17: Homenahem ao Doutor Torquato de Sousa Soares II, 1977, 263-340, el testamento con repr. fot. en pp. 312-321). Tampoco quedó registrado ningún documento de este año en el Libro Registro de la cancillería, no obstante la constancia en el mismo de algunos anteriores. Vid. AZEvedo, R. P. DE «O Livro de registro da Chancelaria de Alfonso II de Portugal (1217-1221)» en AEM 4 (1967) 35-62.

21 Es lo que cabe deducir de las diferencias que se observan entre estos diplomas y los resultantes de la confirmación de 1217, reseñadas en el texto. Sin embargo estas diferencias no han sido valoradas 
Sin embargo, a estas reservas sobre la autenticidad de estos diplomas se sobrepone el hecho de que unos instrumentos muy similares en contenido, formulación y disposición recibieron la sanción real en 1217. También el foral de Coimbra, acorde con los anteriores en la parte fundamental de los mismos, el texto de Alfonso I.

En tanto efecto de una misma actuación regia no puede sorprender la coincidencia que presentan estos tres forais. Pero sí y precisamente por ello se revelan significativas las diferencias que se observan entre el de Coimbra y los de Lisboa y Santarém, ya que éstas no se producen en el cuerpo normativo ${ }^{22}$ (lo que sería comprensible en función de la diversidad local), sino en sus cláusulas protocolarias, esto es, en aquellas que por formularse de acuerdo con las pautas impuestas por la práctica escrituaria de las cancillerías reales cabe esperar mayor uniformidad, más aún cuando como en esta ocasión, es uno el acto objeto de documentación.

En sus cláusulas iniciales, los textos, tras usar de una misma fórmula en la invocación, la trinitaria simple, coinciden en presentar al rey de los portugueses, Alfonso, actuando en solitario, por propia iniciativa y por efecto de su liberalidad. Se dirige a los habitantes presentes y futuros de estos núcleos poblacionales (nombrados como civitas los de Coimbra y Lisboa, como oppidum Santarém) y concreta el alcance de su gracia en la concesión de un fuero que no duda en calificar de bonum, como tampoco en aclarar su finalidad: asegurarse la percepción de unos regalia iura ${ }^{23}$ a perpetuidad, ya que se exigen expresamente mibi et generi meo a vobis et succesoribus vestris.

La singularidad de este preámbulo por su contenido, por el contraste en la terminología utilizada — forum bonum/regalia iura— ${ }^{24}$, también por la ausencia

en el sentido indicado, de ahí la tesis, presentada como hecho cierto, de que los diplomas que se dicen confirmados en 1214 fueron los ejemplares presentados a la convocatoria general de 1217 y que precisamente por figurar en ellos dicha confirmación no fueron destruidos según la práctica habitual (cfr. DMP p. CV y nota LI, p. 745, y AZEVEDO, R. P. DE, loc. cit, nota anterior, p. 39).

22 Cfr. infra 2. 2.

23 Definir los regalia iura precisando cuáles eran fue tarea de los juristas boloñeses Búlgaro, Martino, Jacobo y Hugo que asisitieron a Federico I en la Dieta celebrada en Roncaglia en noviembre de 1158. En ella el emperador se adjudicó la percepción de los mismos en perjucio de las ciudades italianas (cfr. Rahewini gesta Friderici Imperatoris lib. IV, § VIII (ed. WAITZ, G.: Ottonis et Rabewini Gesta Friderici I. imperatoris, Hannover 1912 p. 240, en MGH, SS, 46; y Friderici I. Constitutiones. Curia Roncaliae ed. WeILAND, L.: Constitutiones et acta publica imperatorum et regum inde ab a. DCCCCXI usque a. MCXCVII 1: (911-1197), Hannover 1893, pp. 244-45, en MGH, LC.

${ }^{24}$ La tipificación de un fuero como bueno en tanto superador de unos malos foros anteriores es frecuente en la documentación foral medieval y de hecho tal calificativo lo reciben también los forais que recogen el modelo de Salamanca. No es este el caso de la expresión regalia iura que no figura en ningún otro que no derive de los aquí comentados. En la documentación portuguesa de la época, el rey, tanto en las donaciones de carácter patrimonial a particulares como a grupos de pobladores, suele referirse a la cesión del ius quod ad me pertinet o en el caso de concesiones de coto declarar el territorio libre de tota exactione regali, pero en ningún documento (al menos de las colecciones de esta índole publicadas de Alfonso I y Sancho I) tales derechos se designan como regalia iura. 
del heredero, tiempo ha asociado al gobierno ${ }^{25}$, aparece potenciada por las variantes y adiciones que introducen los fueros de Lisboa y Santarém. Las variantes se encuentran en la cláusula inicial que tras la invocación precede a la intitulación regia. En Coimbra figura una notificación de fórmula general y simple, en tanto que en los otros se opta por una breve arenga ${ }^{26}$ alusiva al origen divino y carácter gracioso del poder, en plena coherencia con la intitulación real que hace a Alfonso rey de los portugueses, no como en Coimbra (y en general en los documentos de la cancillerías de Alfonso I y de su hijo) por la gracia de Dios, sino por expreso designio divino —divino nutu— ${ }^{27}$. Y es aquí, tras la intitulación, donde encuentra cabida un elemento nuevo. Se trata de una breve pero expresiva y un tanto extemporánea referencia a la conquista y repoblación de los lugares respectivos, que, sin embargo, se presenta como antecedente del acto que se documenta $^{28}$. Redactada, lógicamente, en tiempo pasado, nos ofrece la imagen de un rey esforzado e inteligente que dirige a sus hombres a la consecución de un bien que se percibe de orden espiritual: devolver los lugares al culto cristiano, esto es, enlazando con la intitulación, un elegido que no defrauda las expectativas divinas. Es además un rey agradecido y magnánimo que no duda en retribuir a sus colaboradores — meis hominibus atque vasallis et alumnis - con el fruto de la empresa en unos términos —ad habitandum iure bereditario- que nos sitúan (sorprendentemente) ante una práctica de donadío con fines repobladores ${ }^{29}$. En

25 Vid. supra nota 17.

26 Según. Azevedo, R. P. de: «A Chancelaria régia portuguesa nos séculos XII e XIII. Linhas gerais da sua evolução», en RUC 14 (1940) 72, este elemento es extraño a los usos de las cancillerías de Alfonso I y de Sancho I .

27 Una fórmula similar -divinu nutu protectus-, aplicada a Alfonso VI ostentando el título imperator, figura en un documento de este rey en respuesta a una solicitud de los habitantes de Coimbra, confirmándoles en la posesión de sus heredades según lo establecido por el conde Sisnando en el momento de la repoblación, datado el 29 de mayo de 1085 (ed. Livro Preto. Cartulário da Sé de Coimbra. Edição crítica. Texto integral. Director e coordenador editorial RoDRIGUES, M A., Director científico, CosTA, A. de J. DA, Coimbra, 1999, n 14, pp. 23-27; sobre el uso por la cancillería de Alfonso VI de esta y otras fórmulas similares, GAMBrA, A. : Alfonso VI. Cancillería, Curia e Imperio I. Estudio, León 1997, pp.191-93). Sin embargo aunque esta fórmula se tiene por extraña a los usos cancillerescos portugueses (cfr. SOUSA SOARES, T.: «O foral concedido a Coimbra, Santarém e Lisboa em 1179» en ACAdemia Portuguesa Da Historia, Anais, $2^{\text {a }}$ serie 10 (1960) p. 186), no obstante se encuentra en un diploma real datado en 1175 en el que Alfonso I hace donación al monasterio de Lorvão de la villa de Abiul (ed. Reuter, A. E, Chancelarias [cit. supra nota 17] n ${ }^{\circ} 235$, pp. 353-55). Este documento también se inicia con la invocación trinitaria y una arenga similar a la de los fueros de Santarém y Lisboa. Por otra parte, estos preámbulos presentan cierta similitud en su composición -arenga inicial relativa a la justicia, e intervención divina para con el otorgante (divino oraculo eruditus)- con el foral de Thomar de 1174 y los varios que ofrecen este texto, Castelo da Foz da Zerere (1171), Pombal (1176), Oure (1189), Torres Novas (1190), Arega (1201) y Figueiró (1204). Cfr. PMH, LC.

28 Los textos enlazan ambas actuaciones con el término idcirco.

29 Una declaración de este tipo resulta insólita en fueros de concesión real como éstos, pues lo habitual en caso de donaciones es que la iniciativa repobladora y la concesión de fuero parta de los beneficiados que se han comprometido a ello, lo que en ocasiones se hace explícito en el propio documento, como es el caso del foral de Pinhel (1191) en el que su otorgante el prior de Santa 
suma, un párrafo denso ante el que es difícil eludir la extrañeza por el intento que entraña de recuperar con tintes de heroicidad la memoria histórica de unos hechos ya lejanos $(1147)^{30}$ para explicar una actuación regia presente, por otra parte, nada excepcional. Un párrafo que, sin embargo, cobra sentido a la luz de las palabras con las que Alejandro III se dirigía a su karissimo in Christo filio Alfonso, illustri Portugalensium Regi en la bula Per venerabilem, pues se revela como un trasunto del ideario contenido en ésta, tanto en lo referente a la valoración de sus campañas militares contra los musulmanes ${ }^{31}$, como por el aprecio de sus cualidades personales ${ }^{32}$, sin obviar el matiz providencialista ${ }^{33}$.

La cláusula conminatoria así como en el escatocolo las de datación y roboratoria no dan lugar a reparo alguno tanto por la identidad de formulación en los tres textos, como por ajustarse a los usos de la cancillería ${ }^{34}$. Sí los hay respecto de la relación de confirmantes, ausente en el texto conservado de Coimbra (se ha estimado que por defecto de trasmisión ${ }^{35}$ ) y formando elenco con las procedentes de los otros textos integrados en los diplomas, en los de Lisboa y Santarém. El análisis comparativo de las relaciones nominales de uno y otro y la identificación de los personajes mencionados en ellas ha permitido a los estudiosos reconstruir hipotéticamente, mediante la conveniente adecuación cronológica, las de cada uno de los instrumentos integrados en los diplomas y por tanto la del foral de $1179^{36}$. Sin embargo el que varios de los personajes de la relación hubieran podido confirmar documentos de los reyes Alfonso y Sancho permite albergar dudas respecto de esta reconstrucción ${ }^{37}$.

Maria de Ribadavia concede vobis hominibus que uolueritis habitare in Pinel tam presentibus quam futuris... kartam de foro, per mandatum domino regi Santio Portugallia (ed. PMH, LC, pp.481-82). No obstante los términos empleados recuerdan al documento de Coimbra cit. supra nota 27).

30 Este anacronismo ha llevado a algunos autores a relacionar la concesión de estos forais no con su conquista, sino con la recuperación de Santarém por Yusuf y el ataque a Lisboa en 1171; cfr. nota a su edición en $P M H$, cit. supra nota 6, y CAETANO, M.: A administração, pp. 11-12.

31 Manifestis probatum est argumentis quod per sudores bellicos et certamina militaria inimicorum christiane sicut bonus filius et princeps catholicus multimoda obsequia matri tue sacrosancte ecclesie inpendisti dignum memoriam nomen et exemplum imitabile posteris derelinquens.

32 Proinde nos attendentes personam tuam prudentia ornatam justicia preditam atque ad populi regimen idoneam...

33 Equum est autem ut quos ad regimen et salutem populi ab alto dispensatio celestis elegit....

34 No obstante cabe destacar como síntoma de relación textual inmediata entre los diplomas de Santarém y de Lisboa confirmados en 1214, el que en ellos en la mención del rey en la roboratoria el título domno aparezca postpuesto al nombre del rey.

35 Cfr. Reuter, A. E.: Chancelarias, ${ }^{\circ} 245$, p. 371, y DMP, nota LVII, p. 768.

36 Cfr. DMP, nota LVII, p. 768

37 Ninguna ofrece la presencia en el foral de 1179 del canciller real Pedro Feijão que ejerció el cargo entre 1169 y 1181 (vid. CosTA, A. de J. DA: «La Chancellerie», p. 149) ni la de los obispos Fernando de Porto (1174-1185), Bermudo de Coimbra (1177-1182) y Álvaro de Lisboa (11681184) (vid. Gams, P. B.: Series episcoporum Ecclesiae Catholicae, Regensburg, 1873-1886; reimpr. anast. Graz, 1957), como tampoco la ausencia en el mismo del canciller Julião Pais, que sucedió en el cargo a Feijão, y la del electo de la sede de Lisboa Sueiro Anes. Pero no es así respecto de otros personajes susceptibles de identificación (cfr. DMP nota LVII, pp. 768-69). 
Inseguras también se perciben las conjeturas establecidas por la crítica respecto de la confirmación de ambos diplomas por Sancho I y las ampliaciones posteriores en el de Santarém. Sobre la primera, que constaría de las cláusulas roboratorias del documento anterior, de las rúbricas de algunos confirmantes y en el de Lisboa también de un número amplio de testigos del ámbito local ${ }^{38}$, así como el sello rodado, se ha supuesto realizada sobre el diploma originario de Alfonso I entre los meses de mayo de 1186 y 1187, lapsus de tiempo mediante entre el nacimiento de los infantes Alfonso y Enrique. Sin embargo este aserto, sin duda basado en la leyenda del sello, no tiene en cuenta la contradicción que ésta encierra respecto del enunciado de la cláusula confirmatoria ${ }^{39}$. De seguirse ésta, habría que fijar como fecha límite de esta primera intervención de Sancho I el mes de mayo de $1186^{40}$. Por lo que hace al capitulado normativo fruto de una segunda intervención de Sancho I y la cláusula sobre prendas introducida entre las columnas de confirmantes se ha estimado posterior a septiembre de 1198, en atención a la ausencia de la reina, en tanto que el término ad quem se establece en agosto de 1204, (fecha de la carta patente de Lisboa), si bien el distinto tipo de letra empleado en la última disposición ha llevado a considerar para lo anterior como fecha probable el año 1200, así como también para la factura del diploma. Sin embargo, frente al empeño en la datación de estos elementos del diploma santarense no deja de sorprender la falta de interés ya no por explicar, sino ni siquiera por destacar o manifestar extrañeza ante el hecho de la ausencia en estos documentos de las cláusulas de sus respectivos escatocolos, más allá de la incorporación de unos nombres de forma un tanto anómala, sobre todo cuando la presencia de dichos elementos se vincula a la elaboración misma del diploma ${ }^{41}$. Por otra parte cabe advertir que si bien la carta patente de Lisboa contiene una referencia expresa a una concesión anterior a Santarém, tal como ésta se formula en el contexto de la norma sobre prendas, parece que ha de entenderse solamente respecto de dicha cláusula y no de la totalidad del documento, así como también que la colocación de esta norma y la siguiente y última relativa al servicio de los peones en la nave real tras la data permite suponer una fecha posterior para las mismas ${ }^{42}$. Además

38 Tal se deduce de la disposición de los confirmantes en el diploma confirmado en 1214, no obstante, como ya se ha advertido (supra nota 14) en el de 1217 las cláusulas de ésta de Sancho I, situadas a continuación de la relación nominal se presenta acompañada de sólo tres confirmantes, el mayordomo real Juan Fernández, Mendo González y Suero obispo electo de Lisboa.

39 Cfr. DMP, nota LVII, pp. 763-64. Azevedo no parece haber caido en la cuenta de esta discordancia pues en todo momento de su escrito afirma que en esta intervención el rey actua con su esposa e hijos sin justificarlo, lo cual no deja de sorprender, dada la atención que presta a (y valoración de) la fórmula de la segunda intervención en cuanto a la ausencia de la reina.

40 Fecha a partir de la cual los diplomas registran la existencia del príncipe Alfonso (vid. DMP, loc. cit. supra, nota anterior). El dato ofrece cierto interés en relación con la presencia de unos u otros confirmantes en cada uno de los instrumentos recogidos en el diploma.

41 Cfr. DMP, pp. 764-67.

42 Facta fuit hec carta apud Vimaranes mense Augusti Era $M^{a} C C^{a} X(L)^{a} I I^{a}$. Et istud concedo vobis quod apud Colimbriam concilio de Sanctaren concessi, scilicet, ut quicumque pignoraverit... Concedo etiam 
en este punto debería tenerse en cuenta el hecho de que la carta patente de Lisboa (y por tanto su contenido normativo) se presenta como un acto de reparación de los agravios inflingidos a los vecinos por la actuación abusiva de las autoridades reales e incluso de otras comunidades vecinales en contravención de la carta del concejo ${ }^{43}$, lo cual implica una situación concreta que de haberse producido también en Santarém habría quedado igualmente reflejada en el documento respectivo. Dado que no es así parece insoslayable plantear, cuanto menos, la posibilidad de una relación textual entre estos instrumentos inversa a la admitida comúnmente ${ }^{44}$.

\subsection{Su crítica interna}

Según se nos dice en sus preámbulos el objeto de estos forais es fijar las exigencias de Alfonso I para con los habitantes de los núcleos de población a los que van dirigidos, que se cifran en la percepción de unos determinados derechos. A tenor del capitulado normativo que se desarrolla a continuación, estos derechos, previamente identificados como regalia iura y demandados a perpetuidad son unos mismos para las tres poblaciones ya que las normas, en número relativamente amplio, que integran sus respectivos textos forales ${ }^{45}$ no pre-

vobis ut nunquam intert in navigium... La distinta procedencia textual de estas normas respecto de las anteriores aparece tambien reflejada en el uso del término concedere en lugar de mandare como figura en todo el cuerpo dispositivo anterior. Asimismo ha de tenerse en cuenta que esta carta se conoce a través de su transcripción en el foral de Lisboa (vid. el regesto que acompaña a su edición en Docs. Sancho I, $\mathrm{n}^{\circ} 155$, pp. 242-243).

43 Et vicini vestri... ostenderunt mei quasdam rancuras quas habeatis et quod in quibusdam eiciebant vos de vestra carta. Que esta mención a una carta haga referencia al fuero de 1179 parecería lógico dado que no se tiene conocimiento de ningún otro instrumento de esta naturaleza; sin embargo, que Sancho I se refiera a la carta como propia de las autoridades y vecinos a los que se dirige sin aludir a su predecesor, que los supuestos ahora regulados no se correspondan con los de aquél salvo en un solo caso, -la disponibilidad de la almotazaría, que ahora se estipula plena por parte del concejo- y que en su conjunto revelen un marco institucional considerablemente más desarrollado inclinan a pensar en la total independencia de la carta patente y la aludida del concejo respecto del foral de Alfonso I. La actuación indebida de las autoridades se desprende de la formulación de la segunda clausula normativa: Mando etiam ut nec meus pretor ville nec pretor navigiorum nec aluaziles nec aliquis alius audeat afforciare aliquem bominem...

44 Para Rui de Azevedo (DMP nota LVII, p. 765) partiendo del carácter original de los diplomas que aparecen confirmados en 1214 , no cabe la menor duda de la relación textual inmediata y vicaria del diploma de Lisboa respecto del de Santarém sin que tal aserto haya sido objeto de contradicción hasta la fecha.

45 Ninguna de las ediciones presenta los textos divididos en parágrafos. El número de rúbricas que figura en estos forais ( 41 en el de Santarém y 33 en el de Lisboa) resulta insuficiente a la hora de calibrar desde una perspectiva cuantitativa el contenido de estos textos, ya que bajo éstas puede englobarse una serie más o menos amplia de preceptos. Una distribución de las normas, quizá prolija en exceso, pero útil para el análisis comparativo de estos textos, permite establecer en 75 el número de 
sentan diferencia sustancial alguna en su contenido y formulación ${ }^{46}$, aunque sí en su ordenación, en medida escasa, pero suficiente como recurso argumental del debate historiográfico sobre el carácter primigenio de las normas de un foral respecto de los otros ${ }^{47}$. Desde una perspectiva de conjunto el contenido de estos textos, más allá de cubrir el objetivo concreto previamente expresado, ofrecen al estudioso escaso interés, pues los supuestos planteados y las soluciones de sus normas, expresados siempre de forma sucinta y en ocasiones poco clara, apenas si dejan entrever algo más que un orden establecido para una comunidad vecinal asentada sobre los principios de igualdad de fuero y de protección de sus miembros frente a los extraños. En ella los caballeros se constituyen en referente social de otros grupos tanto por lo que se refiere a la obligación de prestaciones para con el rey y la comunidad, como al disfrute de exenciones. En definitiva, una organización municipal propia de los concejos de frontera, que en esta ocasión los textos, frente a lo que sería de esperar, nos muestran en un nivel de desarrollo institucional parco en contraste con el ambiente de actividad artesanal y mercantil que sus normas reflejan ${ }^{48}$.

Como sorprendentes se revelan algunos aspectos en la formulación de estas normas a la vez que ilustrativos de la naturaleza y carácter de este texto. Tales como:

- el que sus disposiciones aparezcan en todo momento redactadas en o para una villa, condición que, como es sabido, no era la de Coimbra ni la de Lisboa. Es cierto que algunos documentos regios dirigidos a esta última ciudad la mencionan como villa, no así para Coimbra ${ }^{49}$, pero

las mismas. Las referencia numéricas a parágrafos que figuran en este estudio responden a esta división, sin duda escasamente expresiva puesto que ninguna edición ofrece los textos distribuidos en parágrafos, pero que en todo caso puede orientar al lector en la localización de las normas.

46 Las diferencias de toda índole se producen siempre entre el de Coimbra y los de Santarém y Lisboa, ya que éstos no las presentan entre sí. En orden a su contenido y formulación se reducen a dos: en el enunciado del supuesto de agresión en la plaza (§ 20) en el que los de Santarém y Lisboa introducen la variante de empleo de armas, aunque no como una adición, sino sustituyendo el termino hominem en Coimbra por el de armis. La segunda se da al fijar la cuantía del portazgo sobre determinados productos (aceite, cueros, cera, añil etc; § 33) en lo que el foral de Coimbra se remite a su fuero y costumbre, en tanto que los de Santarém y Lisboa establecen medio maravedí.

$47 \mathrm{La}$ alteración en el orden de exposición de las normas se da respecto a los supuestos de agresión con espuelas (C $§ 5$; S-L tras la data, $§ 74)$, contribución del cavón en concepto de yugada (C § 14; S-L § 35), caloña por hurto (C § 25- S-L § 65) y condición de los oficiales de las naves (C § 73; S-L tras la data $§ 75)$. En relación con el debate sobre la prioridad foral, dando respuesta a otras posiciones cfr. SOUSA SOARES, T.: «O foral» cit. supra nota 27. Recoge el estado de la cuestión sin nuevas aportaciones CRUZ CoelHo, $\mathrm{M}^{\mathrm{a}} \mathrm{H}$.: «A proposito do foral de Coimbra» en Arquivo Coimbrao 27-28 (1972-1980) 329-346.

48 Una apreciación similar en cuanto al alcance del contenido institucional de estos textos en Caetano, M.: A administração pp. 12-19.

49 Así la carta patente de 1204 (cit. supra nota 15) y la de diciembre de 1210 regulando el relego (ed. Docs. Sancho I n ${ }^{\circ} 196$, pp. 202-3), sin embargo un documento unos meses anterior que 
fuera de un modo u otro, lo que no encuentra explicación y más tratándose de documentos expedidos por la cancillería real es la incoherencia en este punto de las cláusulas normativas con las protocolarias, pues si los textos de Coimbra y Lisboa van dirigidos a los habitantes de dichas civitates $^{50}$, la intención de evitar en éstas el término villa se hace más evidente, por no justificado, en el de Santarém ${ }^{51}$ que lo sustituye por opidum, si bien en la frase inmediata aquél se impone en el genero del pronombre usado en lugar de este último ${ }^{52}$;

- el que tratándose de un texto que se dice concedido por Alfonso I, el rey se presente actuando en primera persona y con carácter imperativo en diez de las 16 normas en que se le menciona expresamente, en tanto en las otras seis la referencia se hace en tercera persona apareciendo como receptor o agente pasivo de las mismas $^{53}$;

- el uso indistinto del sueldo y el maravedí a lo largo de todo el capitulado ${ }^{54}$;

- la utilización indistinta de los significantes latinos y romances para determinados significados, asimismo a lo largo de todo el capitulado. Es el caso de domus/casa ${ }^{55}$, pretor/alcaide ${ }^{56}$, miles/cavaleiro ${ }^{57}$, honor/cavalaria ${ }^{58}$,

recoge la pesquisa realizada en torno a esta cuestión por orden del rey ( $\mathrm{n}^{\circ} 193$, pp. 295-96), el término empleado en todo momento es el de civitas. Respecto de Coimbra tanto el documento de Alfonso VI de 1085 (cit. supra nota 27), como el foral de 1111 (ed. DMP no 25, pp. 32-33) y las posturas del concejo de 1145 (ed. PMH L C pp. 743-44) hacen siempre referencia a la civitas.

50 En el caso de Coimbra esta impresión se refuerza en la datación tópica, en la que para evitar la reiteración se recurre a eadem civitatem.

51 No obstante en el foral de Alfonso VI (ed. PMH, LC, pp. 349-50) se utiliza el término civitas.

52 Ego Alfonsus... opidum de Sanctarem sarracenis abstuli et eam Dei cultui restitui ...

53 Siguiendo el foral de Coimbra el rey se presenta actuando en $\S 1$ : Do itaque vobis pro foro ut...; $\$ 10$ De iugata vero hoc mando...; $\$ 55$ Militem ... cui meus dives homo...; $\$ 57$ Et meus nobilis homo qui...de me tenuerit ; $§ 58$ De casis quas mei nobiles homo vel...; $\$ 61$ De cavalgada...dividant mecum in campo; $\$ 64$ Qui autem ministeriales...veniant ad meas tendas et faciant mihi meum forum; $\S 71$ Portagia vero... et vobis relinquo; $\S 73$ De navigio vero mando...; y $\S 74 \mathrm{Hec}$ itaque omnia prescripta vobis pro foro do et concedo. El rey aparece mencionado en tercera persona en $\S 8$ Qui relegum vini regis ruperit et in relego suum; $\S 23$ Et illi ...pectent...medietatem scilicet regi...; § 24 Et eant in appellitum regis et nullum....regi ; § 25 Et homines...si furtum...medietatem regi; $\S 54$ De atalaia de villa debet Rex...; $\S 69$ Milites...in exercitu regis.

${ }_{54}$ El sueldo figura en $\S \S 1,4,5,6,8,18,19,21,23,32,48$; el maravedí en $\S \S 2,3,31,32$ y 33 (éste último no en el de Coimbra, pero sí en los paralelos de Santarem y Lisboa -§32-).

55 Se utiliza domus en $\$ \S 2,21,42,48,56,63$ y casa en $\$ \S 1,58,62$ y 64.

56 El término alcaide aparece en $\$ \S 26,57,60$ y 73 y el de pretor en $\$ \$ 56$ y 66. Este último y no alcaide es el que figura en los documentos de Sancho I incorporados a los forais de Santarém y Lisboa. Rui de Azevedo, al tratar de la falsificación del primer foral de Leiria, (Documentos falsos de Santa Cruz de Coimbra (séculos XII e XIII), Lisboa 1935) sitúa en 1150 el paso del uso del término de origen árabe alcaide al latino pretor. Sin embargo aquél se recuperó en la lengua vernácula como sinónimo de pretor, como puede apreciarse en la versión romance del foral de Santarém adaptada para Borua que acompaña su edición en $P M H, L C$.

57 Frente a miles, el término romance cavaleiro se utiliza sólo en $\S 15$.

58 El término honor aparece utilizado en $\$ \S 40$ y 41 y cavalaria en el siguiente. 
appellitum/cavalgada 59 ;

- el recurso ocasional a una terminología que por una u otra razón se antoja extraña en este marco textual. Así ocurre, a mi entender, con el término parceiro, que aparece en la misma norma que el de cavaleiro antes destacado, y ello no sólo por tratarse de una voz romance, sino por su baja incidencia en los textos forales ${ }^{60}$. Y más aún con el de naturales no tanto por esta razón ${ }^{61}$, como por entrañar un concepto desarrollado por el derecho común ${ }^{62}$.

El conjunto normativo procedente de la actuación de Sancho I que recogen los forais de Santarém y Lisboa bajo formas documentales diferentes pero con plena literalidad ${ }^{63}$, no presenta ninguna anomalía en su formulación. Redactadas en primera persona, tiempo presente y con carácter imperativo sus disposiciones van dirigidas a fortalecer la autonomía municipal y en su conjunto revelan un marco institucional considerablemente más desarrollado, tanto en el orden sustantivo como funcional, que el fuero de 1179. En todo momento la identidad entre ambos textos es total, salvo precisamente en la norma que el texto de Lisboa reconoce su origen santarense con todo lujo de detalles ${ }^{64}$. Las variantes que se constatan no son baladíes pues afectan al planteamiento del supuesto y a la solución ${ }^{65}$.

59 El término appellitum figura en $\S 24$, en tanto cavalgada en $\$ \S 60$ y 61. También el mismo concepto figura bajo el término exercitum en $\S 39$ de Santarém y Lisboa o exitum en $\S 41$ de Coimbra.

60 Exceptuados los textos forales que siguen este modelo, este término aparece sólo en el foral de Ericeira fechado en 1229 (ed. PMH, LC, pp. 620-21). También excepcional se presenta el uso del verbo aparzare que utiliza el foral de Penacova concedido por Sancho I en diciembre de 1192 (ed. Docs. Sancho I, no 62, pp. 96-98).

${ }_{61}$ Como en el caso anterior el término naturales aparece sólo y precisamente en el foral de Coimbra de 1111 (cit. supra nota 49) y, como es lógico en el idéntico de Soure (ed. DMP no 26, pp. 33-34).

62 A partir de la ley Cives del Codex (10, 40, 2; http://www.thelatinlibrary.com/justinian). La doctrina sobre la condición de naturaleza y los modos de adquirirla se encuentra recogida por Partidas 4 , 24, 1-2; cfr. también la glosa de Gergorio López a estas leyes, así como a 3, 2, 32 (ed. Salamanca, por Andrea Portonaris, 1555; facs. Madrid, BOE, 1974 y 2004; web http://bibliotecaforal.bizkaia.net/ search*spi/tsiete+ partidas/tsiete + partidas)

63 La plena coincidencia sólo se ve afectada por la adecuación a las circunstancias locales en su segundo párrafo ya que en Santarém no ha lugar a la presencia de un pretor navigiorum, y también en el planteamiento y solución del párrafo relativo al procedimiento sobre la prenda que en Lisboa se presenta como adición a la carta patente y en el de Santarém se inserta entre las columnas de confirmantes.

64 Vid. supra nota 42.

65 El texto de Lisboa hace explícito el procedimiento en el enunciado del supuesto y duplica la pena en la solución. 


\subsection{Conclusiones}

De tal complejidad, de tanta incoherencia como pone de manifiesto la crítica de estos documentos no cabe otra conclusión que la de ya no dudar de la autenticidad, sino la de aceptar el carácter apócrifo de los mismos tanto por lo que se refiere a los diplomas que se dicen confirmados en 1214, como de los documentos que en ellos se recogen, hecha salvedad de la carta patente al concejo de Lisboa de 1204.

Por lo que hace a los diplomas, los argumentos a favor de su formación en la cancillería de Sancho I y la reconstrucción hipotética del proceso resultan invalidados por la presencia del sello real anacrónico y de unas rúbricas ajenas por completo a la práctica de las cancillerías reales. También por la irregularidad diplomática que supone la refundición en un solo cuerpo de las relaciones de confirmantes correspondientes a las diferentes intervenciones y por la ausencia de las cláusulas de datación y roboratorias de, precisamente, los documentos más próximos a la supuesta fecha de su elaboración. Demasiados errores que achacar a la impericia de los escribas; demasiadas anomalías que reprochar a un canciller real, más aún trátandose de una personalidad como la de Julião Pais ${ }^{66}$.

Del anterior análisis del texto atribuido a Alfonso I cabe deducir que se trata sin lugar a dudas de un falso de cancillería, pero también lo es en el sentido de no proceder, tal como ha llegado a nuestros días, de una concesión real. Sin duda éste es el origen de algunas de sus normas, al menos de aquellas en las que el rey se presenta actuando en primera persona, en tanto otras, de formulación impersonal, recogen la costumbre y usos de la tierra de Beira ${ }^{67}$. Aunque se acepte como lo más probable, no puede darse por seguro que las normas de autoría regia deban atribuirse a Alfonso $\mathrm{I}^{68}$, como tampoco, de ser así, que todas ellas procedan de un solo documento ${ }^{69}$. De este cúmulo de inseguridades no se libran, lógicamente, los factores circunstanciales de tiempo y lugar, pues

66 Julião Pais figura en los diplomas entre la relación de confirmantes de los forais entre los nombres de la primera columna intitulándose notarius domini regis y actuando como canciller de Alfonso II en la confirmación de 1214. Su actividad al frente de la cancillería regia se desarrolla entre 1181 y 1215 . Sobre su personalidad, su formación jurídica, posiblemente en Bolonia y su ascendiente sobre la familia real cfr. Nobre Veloso, $\mathrm{M}^{\mathrm{a}} \mathrm{T}$.: D. Afonso II. Relações de Portugal com a Santa Sé durante o seu reinado, Coimbra, 2000, pp.187-190; en relación con su actividad documental, AZEVEDO, R. P. DE: «A Chancelaria», pp. 53-57 y 70-72 y CosTA, A. de J. DA: «La Chancellerie» pp. 147-153.

67 Asi se induce del paralelismo de varias de estas normas con los forais similares de Castello da Foz do Zerere (1171), Thomar (1174), Pombal (1174), Oure (1180) Torres Novas (1190), Arega (1201) y Figueiró (1204) en los que se hace remisión explicita al fuero y costumbre de la tierra, así como también con el de Penacova (1192) (vid. supra notas 27 y 60, e infra 83).

68 Un capitulado similar es atribuido a Sancho I en los forais de Leiria (cit. supra nota 10) y de Povos datado asimismo en 1195 (ed. Docs. Sancho I, no 84, pp. 133-136).

69 A este respecto podría ser significativo el hecho de que estas normas, unas figuren al comienzo del capitulado en tanto otras, más numerosas, formando serie y con mayor incidencia de términos romanceados se correspondan con el final; vid. supa nota 53. 
tratándose de un texto formado a partir de recensiones normativas diversas nada se opone, pero tampoco asegura que la fecha de 1179 corresponda a alguna de ellas. Asimismo de la lectura de los documentos y de su análisis comparativo ningún otro dato más allá de los apuntados cabe advertir sobre el lugar originario de estas normas ${ }^{70}$.

Cualquiera que fuera su lugar de origen y su proceso de formación, este texto, una vez consolidado en su contenido y formulación fue adoptado por diversas comunidades vecinales y como fuero propio de cada una de ellas obtuvo la confirmación de Alfonso II en 1217 y $1218^{71}$.

\section{OTRA HISTORIA PARA ESTOS FUEROS}

Plantear que la actitud del emperador Federico I en la Dieta de Roncaglia relativa a la aceptación de los privilegios de las ciudades siempre que se probara la razón de los mismos mediante instrumentos legítimos ${ }^{72}$ pudo servir de inspiración, pasado más de medio siglo, a Alfonso II de Portugal para confirmar los

70 No obstante, sobre una posible vía de investigación a este respecto cfr. infra, 3.

71 En el mes de febrero de este año aparece datada la confirmación del foral de Povos. Otros textos que siguen este modelo foral, datados con anterioridad a estos años no fueron objeto de la confirmación real, quizá por no haber sido presentados en la cancillería a este efecto, pero también cabe dudar de su existencia (en la forma que se han conservado) por aquel entonces. Algunos de ellos presentan indicios suficientes para afirmar que se formaron adecuando al modelo adoptado las cláusulas de datación de, posiblemente, su documento fundacional; así el foral de Almada, atribuido a Sancho I en 1190 (Docs. Sancho I n ${ }^{\circ}$ 46, pp. 71-75) reproduce el foral de Lisboa incorporando como parte integrante del mismo las cláusulas de la carta patente de 1204 y el privilegio del relego de 1210 (cit. supra nota 49); el foral de las poblaciones de Alcobaça en el término de Óbidos, datado en 1210 (PMH, LC pp. 547-50), además de hacer referencia expresa al fuero de Santarém (lo cual no se produce con anterioridad a las concesiones de Alfonso III) utiliza una versión del mismo en la que figuraban las rúbricas alusivas al contenido de las normas; en cuanto a los forais de Montemor Velho y Alemquer ( $P M H, L C$ pp. 556-61) que se presentan concedidos por las infantas Teresa y Blanca, y Sancha, respectivamente, en 1212, reproducen el foral de Coimbra con la correspondiente adaptación tópica sin que en el caso del de Montemor se acompañe de la personal con lo que a lo largo del capitulado se mantienen las alusiones a la actuación real. Por lo que hace a la presencia de confirmantes éstos podrían proceder de un documento de concesión genérica del fuero de Coimbra a estas localidades, pues cuando el de Montemor fue confirmado por Alfonso III en 1234 no se refiere a hanc cartam, sino a forum et cartam quam Colinbrien habet et quod Regina dona Tereisa et dona Branca bone memorie iam diu conceserunt et etiam dederunt. Por último el fuero de Vilafranca de Xira (PMH, LC pp. 562-65) sigue fielmente el texto de Povos, si bien omite (como el texto de Alcobaça) las normas relativas a la caballería villana.

72 Rahewini gesta (cit. supra nota 23) lib. IV, § VIII, p. 240: Hisque omnibus in fiscum adnumeratis, tanta circa pristinos possessores usus est liberalitate, ut, quicumque donatione regum aliquid horum se possidere instrumentis legittimis edocere poterat, is etiam nunc imperiali beneficio et regni nomine id ipsum perpetuo possideret. Et his tamen, qui nullo iure, sed sola presumptione de regalibus se intromiserant, XXX milia talentorum plus minusve redditibus publicis per singulos annos accessere. 
títulos que legitimaban a los señores y ciudades y villas de su reino en el uso de los derechos que ostentaban, e incluso que esta confirmación implicara no tanto aceptar unos derechos adquiridos por aquéllos como reconocerlos ex novo por efecto de su liberalidad ${ }^{73}$ podría parecer a priori una hipótesis si no extravagante, cuanto menos arriesgada ${ }^{74}$.

Sin embargo, más que hipótesis se hace evidencia la trasposición del escenario de Roncaglia al espacio luso por parte del autor anónimo de los preámbulos de los forais que nos ocupan para, valiéndose de unos mismos contenidos (la reclamación de los regalia iura y la ordenación del ámbito ciudadano ${ }^{75}$ ) presentar al rey de Portugal (nunca sometido al Imperio, pero sí vinculado históricamente al reino castellano leonés) como imperator in regno suo conforme a los principios del Derecho común sobre la exemptio imperii y el ejercicio de la plenitudo potestatis ${ }^{76}$. Y en este contexto iquién mejor para encarnar este imaginario que el rey Fundador? ¿qué momento más adecuado que el del reconocimiento del reino por Alejandro III y la protección brindada por la Santa Sede? A estos efectos nada importaban los anacronismos. En cambio, para el estudioso de hoy es la distancia que media entre estos acontecimientos y la formulación y desarrollo de los principios antes aludidos por los juristas ${ }^{77}$ lo que obliga a situar

73 Sobre esta interpretación respecto de las ciudades italianas, siguiendo a Vergottini, Pacheco Caballero, F.: «Aportaciones medievales a la noción de autonomía» en Autonomía y soberanía. Una constitución histórica, ed. IGLESIA FerReIRós, A., Madrid, 1996, p. 46. A este respecto, en relación con la confirmación general de 1217 puede resultar significativa la práctica de la cancillería de destruir los documentos presentados para su confirmación y su sustitución por el elaborado sobre él y registrado en los correspondientes libros para tal efecto (cfr. supra nota 21).

74 Más en relación con el hecho histórico apuntado que con la finalidad de la actuación de Alfonso II, pues aunque se desconoce la disposición real que dio paso a este proceder, la relación de esta iniciativa ya sea con las inquiriçoes posteriores, ya con la organización de la cancillería ha dado pie a los historiadores portugueses para considerar que esta medida fue concebida, en palabras de Azevedo («O Livro», p. 42) «mais para o engrandecimiento do poder real e defesa do patrimonio da Coroa, do que para preservaçao de direitos dos beneficiários de tais confirmaçoes»; en el mismo sentido se manifiestan otros autores como SOUSA SOARES, T., s. v. Confirmaçoes en DHP II, p. 153, y Nobre Veloso, Ma T.: D. Afonso II, pp. 194-96.

75 Si Federico I promulgó en Roncaglia la constitución Omnis iurisdictio (ed. COlORNI, V.: «Le tre leggi perdute di Roncaglia (1158) ritrovate in un manoscritto parigino (Bibl. Nat. Cod. Lat. 4677), in Scritti in memoria di Antonino Giuffrè. Vol. I. Rievocazioni, filosofia e storia del diritto, diritto romano e storia delle idee, Milano, 1967, pp. 111-170), estos forais presentan al rey interviniendo en la ordenación de las respectivas poblaciones mediante la concesión de bonos foros.

76 La doctrina de la exemptio imperii tiene su punto de partida en la decretal Per Venerabilem de Inocencio III dirigida a Guillermo de Montpellier en 1202. Aparece recogida en el Corpus Iuris Canonici, Pars Secunda: Decretalium Collectiones 4, 17, 13 (ed. Richter, E. L. \& FrIEDBERG, E., Leipzig, 1881; web http://freespace.virgin.net/angus.graham/GregDecr.htm, sin el aparato crítico). La atribución al rey de los poderes del emperador aparece formulada por el canonista Alano Anglico hacia 1208 en la glosa iuris a la $I^{a}$ Compilatio 2, 20, 7 (= Decretales de Gregorio IX 2, 28, 7) (ed. GARCíA-GAllo, A.: Manual de Historia del Derecho Español II: Metodología histórico-jurídica, Madrid 1984, $10^{a}$ ed., no 1047, pp. 877-79).

77 En relación con los juristas portugueses, cfr. BRANCO, M ${ }^{\mathrm{a}} \mathrm{J}$. V.: «Estados, pátrias e nações nos juristas hispânicos dos séculos XII e XIII» en Cultura 15 (2002) 21-46. 
estos documentos en la forma que nos han llegado en el reinado de Alfonso II en un tiempo próximo al decreto de la confirmación general, si es que no con causa en él ${ }^{78}$. Un tiempo, es sabido, en el que el primer homónimo del Fundador, tras superar una grave crisis política, despliega una serie de estrategias tendentes a consolidarse en el trono y a reafirmar su autoridad 79 . De que estas estrategias se vieron propiciadas por un ambiente cultural idóneo, no limitado al círculo cortesano, son buena prueba estos forais ya que precisamente por haber sido elaborados al margen de la cancillería real se nos ofrecen como fieles exponentes del arraigo social de las doctrinas del Derecho común en relación tanto con el contenido y alcance del poder real como con el valor de la norma escrita ${ }^{80}$.

Establecida la coordenada temporal para estos instrumentos y excluido por la crítica diplomática su origen cancilleresco parece inevitable vincular su formación a los beneficiarios inmediatos de los mismos, esto es, los concejos que asumiéndolos como propios los presentaron a la confirmación real. En cuanto a los beneficios, más allá del casuismo y alcance preciso de sus normas, pueden cifrarse en un concepto, el de seguridad (y no era para menos, dado el pasado reciente ${ }^{81}$ ) por lo que suponen de reconocimiento de una tradición jurídica por la máxima autoridad del reino y también por contar como garantía de una y otro con un documento público, ahora sí debidamente cumplimentado y suscrito por el canciller real Gonzalo Méndez ${ }^{82}$.

A la vista de los textos sólo cabe apuntar alguna conjetura sobre dónde y cómo se llegó a concretar esta tradición jurídica en la serie de normas que los integran. Respecto del interrogante espacial ya se ha aludido a cómo la historiografía tradicional, partiendo de aceptar la data que figura en los documentos (1179, y 1195 en el caso de Leiria y Povos) lo enfoca desde la perspectiva de la extensión de un derecho de ámbito local a otras poblaciones, sin que los argumentos a favor de una u otra de las implicadas en este caso resulten concluyentes. No lo son, sin duda, por defecto de planteamiento en cuanto a la génesis de los textos, pero incluso desde la nueva óptica aportada por la crítica diplomática y la hipótesis de su gestación más o menos inmediata, pero en todo caso próxima, a la orden de la confirmación general tampoco parece factible llegar a

78 El que el decreto regio estuviera o no inspirado en Roncaglia no impide que así lo percibiera el autor de estos preámbulos. Por otra parte, el que hayan llegado hasta nosotros diversos diplomas forales que reproducen este texto datados con anterioridad a 1217 (vid. supra nota 71) no debe resultar significativo ya que no han sido objeto de la crítica diplomática pertinente.

79 Sobre ello cfr. entre otros, Nobre Veloso, $\mathrm{M}^{\mathrm{a}}$ T.: D. Afonso II, cap. VI: «Lançamento das bases institucionais para a centralização monárquica», pp. 177-222.

${ }_{80} \mathrm{Si}$, en palabras de Federico I, al fijar por escrito el derecho debería atenderse a la honestidad, justicia, posibilidad, necesidad, utilidad y adecuación al tiempo y lugar (vid. Rahewini gesta lib. IV, § 4 , p. 327) nuestros fueros no dudan en presentar al rey instando al mayordomo a velar por el cumplimiento del fuero acudiendo ad omnia prescripta et non ad alia.

81 Cfr. Nobre Veloso, Ma T.: D. Afonso II, cap. III y IV, pp.45-23.

82 Colaborador primero y luego sucesor de Julião Pais se mantuvo al frente de la cancillería después de la muerte de Alfonso II. Cfr. Nobre Veloso, Ma T.: D. Afonso II, p. 195. 
una respuesta convincente. Pero quizá sí lo fuera de abordarse el problema del origen de estos forais no como efecto de un proceso de difusión de un derecho local, sino, al contrario, de localización de un derecho aplicado en un ámbito espacial más amplio (en este caso el territorio de Beira) dando lugar a diversas redacciones independientes, algunas de las cuales llegaron a afianzarse como propias de un lugar y difundirse como tales ${ }^{83}$. Las semejanzas entre los forais de que aquí se trata con otros de esta región, en concreto los varios que presentan la formulación del texto de Thomar (1174) y con independencia el de Penacova (1192) inclinan a seguir esta línea de investigación que apunta al entorno de Coimbra como posible foco redaccional del derecho de este territorio ${ }^{84}$.

A tenor de los resultados de la crítica, quienquiera que fuera el autor de este cuerpo normativo, posiblemente un práctico conocedor del derecho de la tierra, pero no tanto de la técnica jurídica, parece haber llegado a este resultado mediante la refundición de diversas recensiones de tiempos diferentes, de las cuales, cuanto menos una tuvo su origen en un privilegio real, quizá de Alfonso I, del que pudo tomar también las cláusulas formales de este tipo documental logrando con ello atribuir tal carácter al conjunto de las disposiciones. Si del texto así formado hubo otras versiones anteriores a la recogida por estos forais ningún indicio se encuentra en ellos, pues las mínimas diferencias que presentan entre sí, de carácter formal ${ }^{85}$, ponen de manifiesto a todas luces que ésta fue tenida por definitiva hasta el punto de que ni siquiera se detecta en ella rastro alguno de una posible intervención del autor de las cláusulas protocolarias de los documentos conservados ${ }^{86}$. Del análisis de éstas trasciende la perso-

83 Situaciones de este tipo están en el origen de la formación de los fueros de la Extremadura y del extenso de Jaca; cfr. BARrero GArcía, A Ma .: El fuero de Teruel. Su historia, proceso de formación y reconstrucción crítica de sus fuentes. Madrid, 1979, y «La difusión del fuero de Jaca en el Camino de Santiago» en SeSma MuÑoZ, J. A. coord.: El fuero de Jaca II: Estudios, Zaragoza, 2003, pp. 113-60

84 Me baso para esta deducción en el hecho de que el referido foral de Thomar (y de las otras varias poblaciones que presentan como propio este mismo texto, cfr. supra nota 27) en una de sus cláusulas se remite a un veterem forum Colimbrie, que si bien parece haberse interpretado como referencia al texto del foral de esta ciudad de 1111 (cfr. SOUSA SOARES, T.: Concelhos, cit. supra nota 4) no es probable que así sea, ya que tal remisión lo es al procedimiento de composición corporal por heridas causadas, (cfr. MERÊA, P.: «Composição corporal (Achêga para a historia do direito penal portugués)» en $A H D E 15$ [1944] 564-70, y en Estudos de Direito Hispânico medieval II, Coimbra, 1953, pp. 195-205) tema no contemplado en dicho foral. Por otra parte, el que en este mismo texto se remita a la costumbre de la tierra y al fuero de la tierra en dos supuestos, el hurto y el relego, y que estos aparezcan regulados asimismo en el foral de Penacova y en los que de aquí se trata de forma expresa y plenamente coincidente entre sí, permite poner en relación la costumbre o fuero de la tierra con el viejo fuero de Coimbra y suponer que la formulación que figura en estos últimos es la de un derecho que tiene a Coimbra como referente.

85 No así en el foral de Povos que prescinde de las cláusulas relativas a la regulación de la iugada y disminuye sensiblemente la cuantía de algunas caloñas.

86 La inclusión en algunas cláusulas de términos que aluden a conceptos acuñados por el derecho común, como es el caso del de naturaleza antes comentado (cfr. notas 61 y 62) ha de interpretarse más desde la formación del texto por acumulación de recensiones de diversa época que 
nalidad de un jurista formado en el Derecho común, interesado en hacer valer en su realidad inmediata unos principios y valores jurídicos, pero también y sobre todo políticos, adquiridos a través de estos saberes nuevos y quizá de su propia experiencia vital. Por otra parte, dado el interés de los concejos en disponer de un documento de esta naturaleza, cabe pensar en un personaje si no interesado directamente en el gobierno de uno de ellos, merecedor de prestigio social e intelectual, y deducir que actuó por encargo de las autoridades vecinales, reservando a su propia iniciativa el procedimiento para llevarlo a efecto. Y es en este espacio de libertad donde encuentra acomodo el papel mediador que parece haber asumido voluntariamente entre los intereses de los concejos y los de la corona en tanto institución que a sus ojos encarnaba con excelencia los principios y valores de las nuevas doctrinas. De su modo de actuar, bien alterando unas cláusulas dadas, o creándolas ex profeso a partir de las fórmulas usuales en la cancillería real y dotándolas de un contenido adecuado a la finalidad buscada mediante el recurso a unos determinados hechos históricos ya se ha hecho cumplida referencia. A tenor de la crítica textual cabe también suponer que la primera redacción (la recogida en Coimbra), más contenida y en la que el recuerdo de la bula alejandrina sólo se deja sentir en la data del documento, pudo no satisfacer plenamente al autor, ya que no dudó en ampliarla para, inspirándose en el escrito papal, dar sentido político al espacio y transmitir al conjunto un cierto carácter de epopeya. Un esfuerzo en modo alguno vano puesto que esta segunda redacción fue la adoptada y adaptada con independencia por las comunidades de Leiria, Povos y Lisboa. En cuanto al foral de Santarém la crítica permite sospechar de su carácter ancilar respecto del de Lisboa por lo que se refiere a la versión recogida en los diplomas de $1217^{87}$. Por lo que hace a los que se dicen confirmados en 1214 la relación de dependencia entre ambos en este mismo sentido resulta sin duda más concluyente ${ }^{88}$.

Como también lo son, a mi entender, los datos antes destacados que conducen a postponer la elaboración de estos últimos (y también del de Leiria ${ }^{89}$ ) a

por la iniciativa de uno u otro de los agentes del documento. De otro modo cabría esperar una intervención más amplia en el cuerpo normativo por parte del autor de los preámbulos.

87 El cotejo textual de estos cuatro forais permite apreciar una serie de diferencias comunes en los de Lisboa y Santarém respecto del de Leiria y Povos, lo cual, de rechazar una relación de dependencia inmediata entre aquéllos, obligaría a presuponer una nueva redacción común a ambas, resultando de ello una tradición textual excesivamente compleja. En cuanto a la relación vicaria del de Santarém la encuentro en el argumento ya señalado sobre la inclusión como privilegio de Sancho I del cuerpo normativo recogido para Lisboa en la carta de 1204. Que éste no figure en el diploma de Lisboa de 1217 pudo deberse a defecto en su escrituración de la cancillería de Alfonso II, pues, de no ser así, no se encuentra sentido a que se recogiera entonces (o en el instrumento presentado por el concejo) solamente la última cláusula de la misma.

88 Así parece deducirse de la inclusión de las rúbricas, marginales en el diploma de Lisboa, en el contexto normativo del de Santarém.

89 Respecto de este diploma de Leiria y su confirmación por Alfonso II de 1214, a los argumentos antes señalados para los de Lisboa y Santarém cabe añadir que aún siendo diferente el 
la confirmación general e incluso al mandato de Alfonso II. La similitud de sus caracteres externos permite suponer para su factura una misma sede, (al menos para los de Lisboa y Santarém) probablemente un escritorio monacal del entorno lisboeta. Que tras esta iniciativa se oculte otra intención más allá de un prurito de prestigio y singularidad por parte de estos concejos es posible. En cualquier caso de lo que no cabe duda es de que la medida surtió efecto ya que en adelante, superadas las coyunturas concretas que dieron lugar a su formación, estos forais, identificados ya como propios de una u otra población, constituirán el referente si no obligado, sí preferente en la ordenación jurídica del Alentejo y el Algarve portugués ${ }^{90}$.

Hasta aquí la otra historia posible de unos textos, trazada a grandes rasgos a partir de sus formas y de sus contenidos, de sus palabras y de sus silencios. Una historia difícil de seguir de no contar con el apoyo inmediato de los propios textos; también difícil de aceptar por lo que supone de contradicción de afirmaciones historiográficas tenidas por verdades, por lo arriesgado de algunas hipótesis, por la debilidad de algún argumento y, en fin, por sus muchos cabos sueltos. Pero una historia (creo) aunque limitada en su alcance, no carente de interés por lo mucho que revela y sugiere sobre unos tiempos de transición y un ambiente cultural en los que sin perjuicio de la tradición la novedad va abriéndose camino, a veces, como en este caso, por senderos un tanto insospechados.

sello y leyenda que en él figura, éstos son también anómalos a la práctica de la cancillería de Sancho I, ya que en ellos figura entre los nombres de los infantes el de Raimundo, caso único en los documentos de Sancho I (o al menos entre los recogidos en la colección diplomática de que se dispone).

90 Cfr. la Carta de los concelhos cit. supra nota 4. La edición de los textos de las localidades en ella señaladas en $P M H, L C$. 